\title{
DISAIN KEKUATAN SAMBUNGAN HOOP PILLAR DAN FLOOR BEARER PADA STRUKTUR RANGKA BUS MENGGUNAKAN SOLIDWORKS
}

\author{
Agus Sasmito \\ B2TKS-BPPT \\ Kawasan Puspiptek Gd 220 Banten \\ Email: agus.sasmito@bppt.go.id
}

\begin{abstract}
ABSTRAK
Keamanan penggunaan sebuah produk kendaraan bus merupakan kebutuhan yang wajib, untuk itu diberlakukan suatu regulasi berbentuk standar yang harus dipenuhi oleh produk. Salah satu standar yang dijadikan acuan untuk penentuan kelayakan kendaraan bus adalah Australian Desaign Rule (ADR). Didalam standar ini diatur tentang kekuatan minimum yang harus dipenuhi sebuah sambungan pada komponen struktur kendaraan antara hoop pillar dan floor bearer yang diketahui melalui proses uji. Untuk mengurangi resiko kegagalan saat uji sambungan maka perlu dilakukan desain untuk membuat suatau sambungan yang tepat. Berkaitan memenuhi kebutuhan langkah desain sambungan yang tepat maka dilakukan suatu penelitian, dimana penelitian ini fokus pada penggunaan solidworks sebagai salah satu software elemen hingga untuk analisa kekuatan sambungan. Untuk mendapatkan alur desain dengan solidworks yang optimal, maka dilakukan penelitian yang dimulai dari pemodelan bentuk sambungan, pemilihan konstrain, memasukan jenis material, pemilihan jenis meshing, metode peletakan beban dan iterasi. Keluaran hasil analisa sambungan dengan solidworks selanjutnya di validasi dengan pengujia pada spesimen. Berdasarkan hasil uji validasi menunjukan bahwa langkah-langkah disain yang dihasilkan dalam penelitian ini sudah benar, terbukti dari hasil simulasi sambungan dimana pada saat model sambungan diberi beban $1000 \mathrm{~N}$ maka terjadi defleksi sebesar 14,14 mm, sangat mendekati defleksi yang terjadi saat uji validasi yaitu sebesar $14 \mathrm{~mm}$.
\end{abstract}

Kata kunci: hoop pillar, floor bearer, solidworks, finite element.

\begin{abstract}
In order to ensure the safety of the bus structure, It's structure specification must conform to any standard or regulation. One of standard that is used as a reference for the determination of the feasibility of a bus structure is the Australian Design Rule. This standard is set about the minimum strength that must be fulfilled a connection on the vehicle structure components such as waist rail and pillar. The connection strength of hoop pillar and floor bearer are known through the testing. To reduce the risk of failure during connection test, it should be designed the appropriate connection. The research is done to obtain the best design step to meet the needs of the appropriate connection design. This research focuses on the use of solidworks as one of the finite element software for structure strength analysis. To get the optimal design of solidworks, the research following steps starting from modeling of connection, constrain selection, input of material, selection of meshing type, loading method and iteration. The solidworks output of the connection analysis is validated by the test on the specimen. Based on the results of validation test show that the design steps generated in this research is correct, as evidenced from the simulation results when connection model is loaded $1000 \mathrm{~N}$ then deflection is $14,14 \mathrm{~mm}$, this simulation result is close to deflection that occurred during the validation test that is $14 \mathrm{~mm}$.
\end{abstract}

Keywords: hoop pillar, floor bearer, solidworks, finite element.

\section{PENDAHULUAN}

Saat ini, terdapat kebutuhan yang besar pada disain struktur bus yang ringan, effisien dan aman untuk aplikasi transportasi [1]. Kendaraan transportasi pada umumnya, dan bus khususnya berada di bawah kondisi tekanan yang cukup berat karena adanya persaingan yang tinggi sesama produsen autobus, adanya regulasi keselamatan kendaraan dari pemerintah dan preferensi permintaan kenyamanan pengguna alat transportasi [2].

Regulasi yang berkaitan dengan disain bus jenis rollover telah dikembangkan dibeberapa negara seperti di eropa, Australia dan Amerika. Hal ini bertujuan untuk membuktikan bahwa pihak produsen bus 
mampu menghasilkan bus dengan kekuatan yang cukup untuk menahan beban tanpa mengalami deformasi [3].

Salah satu standar uji yang digunakan dalam menentukan kelayakan sebuah produk bus adalah Australian design standard (ADR). Didalam ADR pada salah satu poinya yaitu pada paragraf 6.7, ADR 59/00 Part A adalah adanya uji kekuatan sambungan las antara hoop pillar dan floor bearer untuk mengetahui kelayakan sambungan las [4].

Untuk memprediksi kegagalan yang mungkin terjadi selama uji pada komponen sambungan las antara hoop pillar dan floor bearer, maka akan dilakukan analisa dengan menggunakan software finite element (FEM) atau sering juga disebut software elemen hingga [5-7], dalam riset ini digunakan software solidworks untuk melakukan simulasi defleksi dan mode kegagalan yang mungkin terjadi pada sambungan.

Solidworks adalah software simulasi yang memungkinkan setiap perancang dan insinyur untuk melakukan simulasi struktural pada bagian atau rakitan sebuah struktur dengan analisis elemen hingga (FEM). Solidworks mampu memperbaiki dan memvalidasi kinerja dan mengurangi kebutuhan akan prototip atau perubahan desain yang mahal di kemudian hari [8]. Bentuk bus yang dijadikan obyek analisa adalah bus medium seperti ditunjukan pada gambar 1 .



Gambar 1. Bus Medium

Pemodelan sambungan antara hoop pillar dan floor bearer dibuat menggunakan sofware solidworks, untuk mendapatkan hasil yang optimal maka proses anlisa finite elemet harus dilakukan dengan prosedur yang tepat sesuai yang dianjurkan oleh pembuat solidworks. Bentuk model untuk analisa finite element disesuai dengan bentuk yang ada pada persyaratan uji yang ada pada standar Australian Design Rule (ADR) 59/00 Part A Tahun 1992.

Tujuan analisa ini untuk memprediksi kekuatan konstruksi sambungan komponen rangka bus antara hoop pillar dan floor bearer. Hasil analisa ini dapat digunakan untuk memprediksi kekuatan sambungan sehingga sambungan dapat memenuhi persyaratan disain pada standar ADR 59/00 Part A Tahun 1992, selain itu juga untuk menentukan kelayakan operasi serta kemampuan konstruksi sambungan antara hoop hoop pillar dan floor bearer dari segi kekuatan dan kekakuan. Dalam analisa ini, pemodelan dan analisa finite element dilakukan dengan software solidworks, spesimen hanya dibatasi pada komponen sambungan bus antara hoop pillar dan floor bearer. Untuk analisa sambungan digunakan penyederhanaan sebagai berikut :

a. Bentuk sambungan yang diambil untuk analisa FEM dan uji validasi didasarkan pada standar ADR 59/00 Part A Tahun 1992.

b. Pembebanan, tumpuan, dan berbagai kondisi pada analisa dan uji validasi didasarkan pada standar ADR 59/00 Part A Tahun 1992.

c. Cacat las pada sambungan diabaikan.

\section{METODOLOGI PENELITIAN}

Struktur rangka bus terdiri dari beberapa komponen sambungan, dimana tiap komponen disambung dengan proses las. Setiap komponen pada struktur rangka bus memiliki istilah nama tertentu, istilah yang digunakan untuk komponen rangka bus ditunjukan pada Gambar 2. a [4]. Kondisi aktual rangka bus medium dan posisi sambungan yang akan dilakukan pengujian dan analisa ditunjukan pada Gambar 2 .b [4]. 




(a)

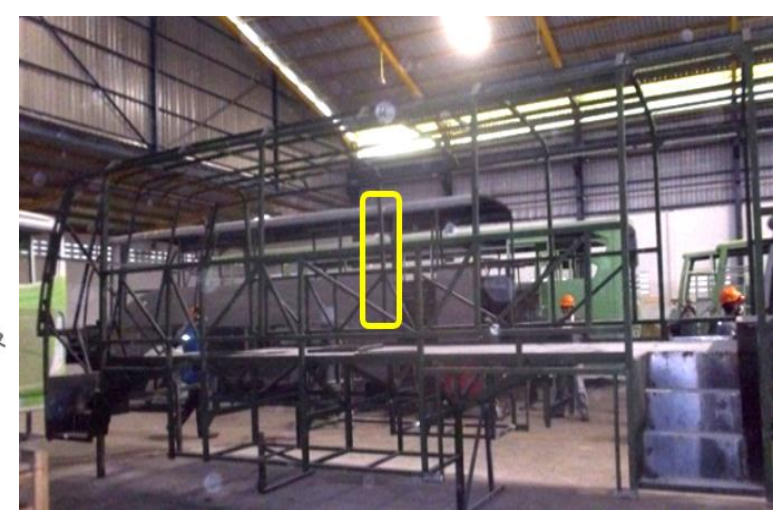

(b)

Gambar 2. Struktur Rangka Bus: (a) Posisi Hoop Pillar dan Floor Bearer Pada Struktur Bus, Dan (b) Floor Bearer Pada Struktur Bus Yang Menjadi Fokus Penelitian

Spesimen sambungan las terdiri dari 2 komponen rangka yang ada pada bus, yaitu floor bearer dan hoop pillar. Floor bearer dan hoop pillar berbentuk batang rectangular hollow. Foto struktur sambungan hoop pillar dan floor bearer ditunjukan pada Gambar 3.

(a)

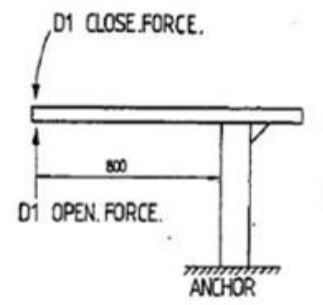

(b)

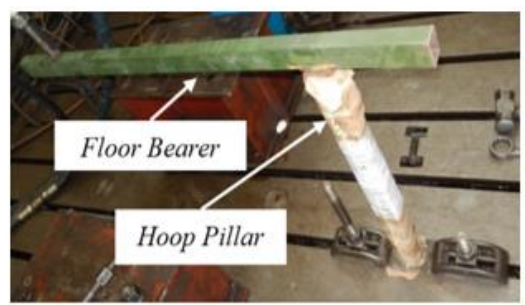

(c)

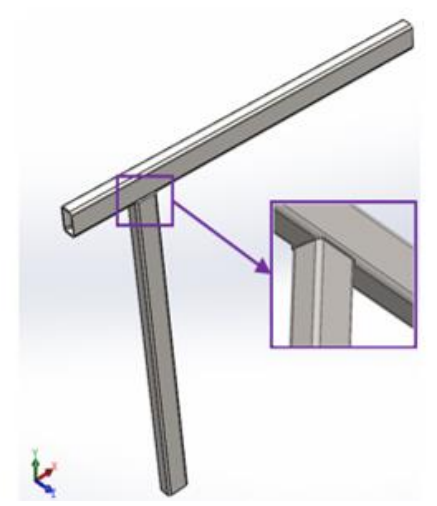

Gambar 3. Spesimen Sambungan Las Floor Bearer-Hoop Pillar: (a) Metode Uji Sesuai ADR, (b) Foto Spesimen Sambungan Las Hoop Pillar dan Floor Bearer, Dan (c) Pemodelan Sambungan Las Dengan Solidworks

Sambungan antara komponen hoop pillar dan floor bearer dibuat dengan proses las. Dimensi dari spesimen sambungan las yang digunakan ditunjukan pada Gambar 4. Dimensi spesimen uji ini disesuaikan dengan standar ADR Part A. 
a)

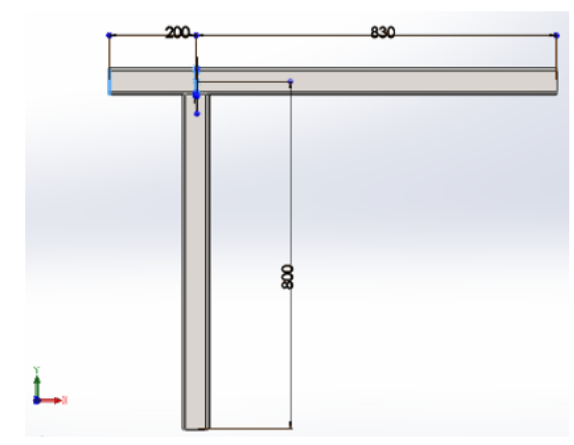

(b)

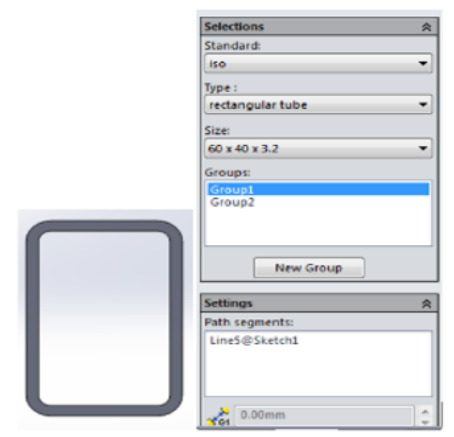

Gambar 4. Dimensi Sambungan Las (Mm): (A) Dimensi Sambungan, (B) Bentuk Dan Dimensi Penampang Batang

Dimensi longitudinal batang adalah sebagai berikut :
Panjang hoop pillar $\quad: 800 \mathrm{~mm}$
Panjang floor bearer : : $1030 \mathrm{~mm}$
Dimensi penampang batang
Bentuk
: rectangular tube
: $60 \times 40 \times 3.2 \mathrm{~mm}$
Dimensi

Metode analitis untuk mengetahui kekuatan statis pada spesimen dilakukan dengan simulasi model sambungan menggunakan software Solidworks, langkah-langkah simulasi yang dilakukan dapat dijelaskan sebagai berikut [9] :
a. Pembuatan model
b. Start New Static Study
c. Pemilihan Material
d. Penempatan tumpuan
e. Penempatan beban
f. Pendefinisian kontak komponen
g. Pembuatan meshing pada model
h. Menjalankan solvers
i. Interpretasi dan Analisa hasil FEM

\section{HASIL PENELITIAN DAN PEMBAHASAN}

Kekuatan spesimen disimulasikan dengan kondisi batas tertentu, selanjutnya dilakukan uji untuk validasi hasil simulasi yang telah peroleh, secara detail proses simulasi dan validasi dijelaskan pada paragraf 3.1 dan 3.2 .

\subsection{Hasil Penelitian}

Untuk mengetahui perilaku dan karakteristik sambungan las, maka dilakukan penelitian berupa analisa numeric menggunakan solidworks, kegiatan analisa yang dilakukan dengan solidworks dapat dijabarkan sebagaimana langkah-langkah pada poin paragraf dibawah.

\subsubsection{Pemilihan Material}

Pada saat pertama kali menu stati study terbuka, maka langkah pertama yang dilakukan adalah menentukan material. Solidworks menawarkan banyak jenis material pada menu library, walau demikian masih juga menawarkan pada disainer untuk memasukan sendiri properties material sendiri seperti yield strength, tensile strength, density dan lainya. Properties material komponen penyusun sambungan las yang dijadikan bahan spesimen ditunjukan pada Tabel 1 . 
Tabel 1. Sifat-sifat teknis material

\begin{tabular}{cl}
\hline Sifat Teknis Material & Nilai \\
\hline Modulus Young & $207000 \mathrm{MPa}$ \\
Modulus Geser & $77000 \mathrm{MPa}$ \\
Poison's Ratio & $0,3 \mathrm{MPa}$ \\
Densitas & $7,85 \mathrm{E}-06 \mathrm{~kg} / \mathrm{mm}^{3}$ \\
Kekuatan Luluh & $245 \mathrm{MPa}$ \\
Kekuatan Ultimate & $400 \mathrm{MPa}$ \\
\hline
\end{tabular}

Proses input data properties material kedalam library solidworks ditunjukan pada Gambar 5.



Gambar 5. Proses Input Properties Material Pada Solidworks

\subsubsection{Penempatan Tumpuan}

Pada menu tumpuan (fixture) menunjukan banyak pilihan untuk menumpu seperti ditunjukan pada Gambar 6.



\section{Gambar 6. Menu Tumpuan Pada Solidworks}

Terdapat 3 jenis tumpuan dalam solidworks, dimana setiap tumpuan memiliki fungsi berbeda, maksud dari jenis-jenis tumpuan itu adalah :

a. Fixed geometry, untuk tumpuan jenis fix 
b. Immovable, untuk tumpuan jenis engsel

c. Roller/slider (Use reference Geometry), untuk tumpuan yang bisa meluncur.

Untuk simulasi tumpuan sambungan las ada gerakan meluncur pada arah tertentu, tapi tidak ada gerakan memutar, maka diambil tumpuan berjenis Immovable dan slider. Proses input data tumpuan kedalam solidworks ditunjukan pada Gambar 7, dimana pada tahap ini dipilih jenis tumpuan yang sesuai di dalam solidworks.

(a)

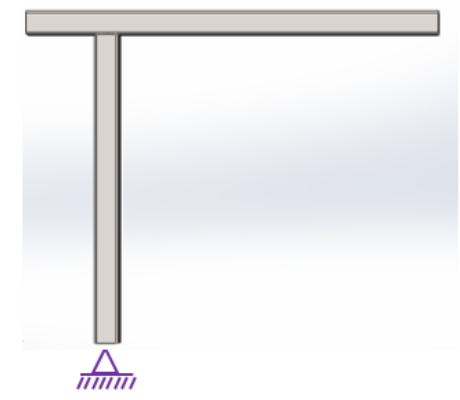

(b)



Gambar 7. Input Tumpuan Pada Solidworks: (a) Penyederhanaan Skema Tumpuan Sesuai Metode Uji Sambungan Las, Dan (b) Aplikasi Tumpuan Immovable

\subsubsection{Penempatan Beban}

Dalam analisa solidworks ini beban yang diberikan pada model sebesar $1000 \mathrm{~N}$, dimana beban gravitasi tidak digunakan. Proses input data beban ke dalam solidworks ditunjukan pada Gambar 8 .

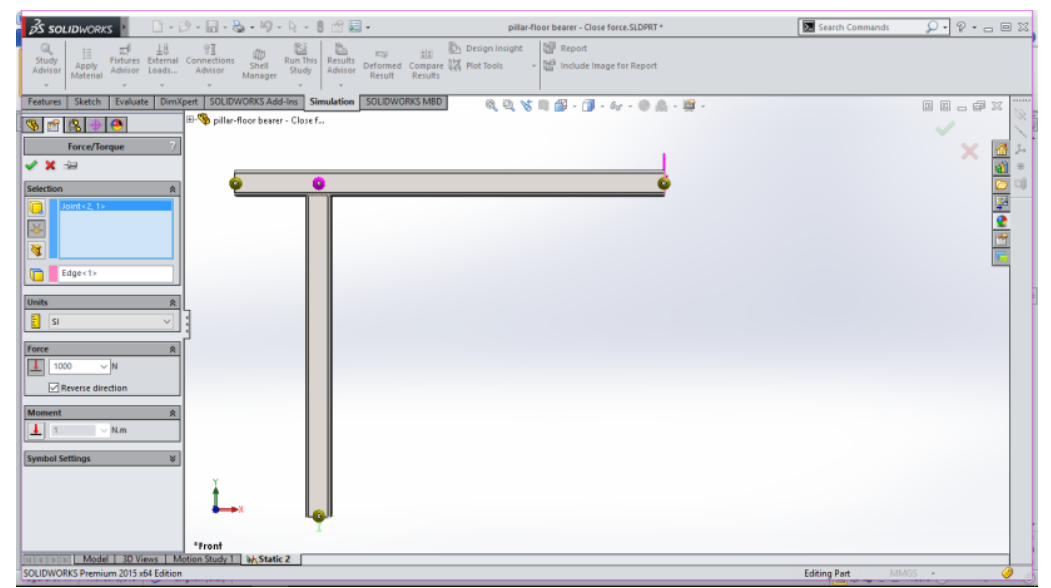

Gambar 8. Input Properties Beban Pada Solidworks $1000 \mathrm{~N}$.

Beban diberikan pada posisi titik simpul di ujung kedua hoop pillar, total beban yang diberikan adalah

\subsubsection{Pembuatan Meshing Pada Model}

Meshing adalah langkah penting dalam setiap simulasi, dan sangat menantang. Hal ini didasarkan pada teknik analisis Elemen Hingga yang memberikan teknik numerik yang andal untuk menganalisis disain teknik. Pada awalnya, model geometri dibuat, selanjutnya model dibagi menjadi potongan-potongan kecil berupa bentuk sederhana (elemen) yang dihubungkan pada titik-titik tertentu (node). Dalam FEM,model dibentuk menjadi jaringan elemen interkoneksi diskrit yang terpisah. FEM mampu memprediksi perilaku model dengan menggabungkan informasi yang diperoleh dari semua potongan elemen yang membentuk model [10]

Model yang telah dibuat dibagi-bagi menjadi bagian-bagian kecil yang disebut elemen, setiap elemen saling menyambung pada suatu titik yang disebut node. Setiap elemen menghasilkan perhitungan tegangan dan regangan. Dimana deformasi dan displasmen dihitung pada node.

Pada 
Gambar 9 berikut memberi ilustrasi perbedaan geometri antara meshing jenis solid dan shell [11].

(a)

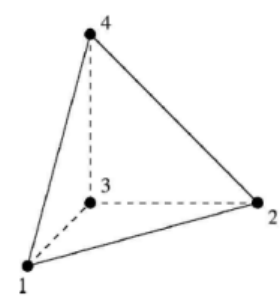

(b)

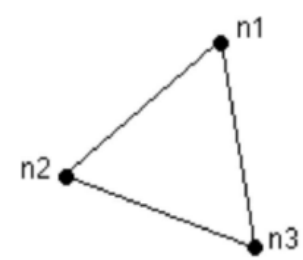

\section{Gambar 9. Jenis Elemen Pada Analisa FEM Solidworks: (a) Tetrahedral Element Untuk Meshing} Continum, Dan (b) Triangular Element Untuk Struktural Meshing

Terdapat beberapa perbedaan antara kedua tipe meshing, yang dinakan derajad kebebasan. Elemen solid memiliki 3 derajad kebebasan yaitu 3 arah translasi sepanjang sumbu x, y, dan z. Elemen shell memiliki 6 derajad kebebasan yaitu 3 arah translasi ditambah dengan 3 arah rotasi terhadap sumbu x, y, dan z.

Model dipotong-potong menjadi element melalui proses meshing, dimana elemen 3D tetrahedral untuk elemen solid, elemen 2D triangular untuk shell dan elemen 1D untuk struktur beam. Meshing hanya berisi satu jenis elemen, kecuali dibuat spesifikasi jenis tipe elemen lain.

Elemen shell cocok untuk model yang memiliki part tipis (sheet metal), batang dan elemen-elemen struktural lainya. Sehingga dalam analisa kekuatan sambungan ini akan digunkan elemen shell, karena pada sambungan terdiri dari komponen hoop pillar dan floor bearer yang terbuat dari batang berongga dengan dinding plat yang tipis. Proses meshing yang dilakukan pada model sambungan hoop pillar dan floor bearer ditunjukan pada

Gambar 10

(a)

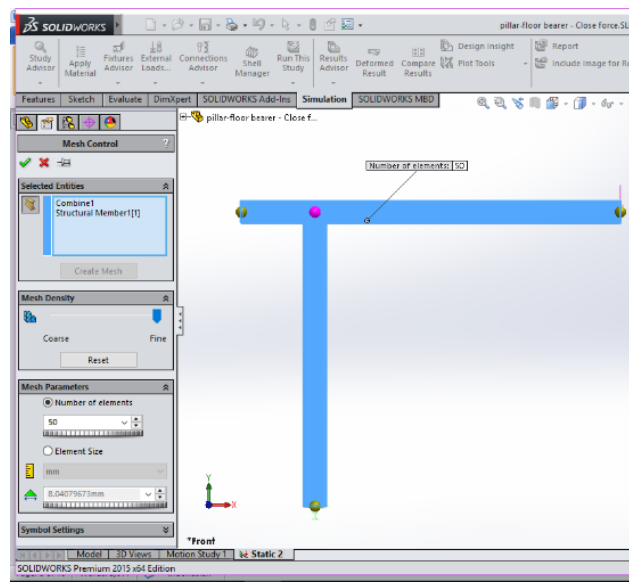

(b)



Gambar 10. Meshing Pada Model Sambungan Las: (a) Pengaturan Dimensi Meshing Pada Model, Dan (b) Hasil Meshing Pada Model

\subsubsection{Menjalankan Solver}

Dalam FEM setiap permasalahan dipresentasikan dalam sebuah persamaan aljabar yang harus diselesaikan secara simultan, metode solusi yang digunakan bisa direct atau iterative [12].

Metode direct sparce memecahkan persamaan menggunakan teknik exact numerical, sedangkan metode iterative memecahkan persamaan dengan teknik iterasi, hasil solver dalam bentuk asumsi dan kesalahan kalkulasi akan dievaluasi ulang. Proses iterasi akan selalu dilanjutkan sampai tingkat kesalahan dapat diterima. Solidworks memberikan empat opsi berbeda pada tahap solvers yaitu : 
a. FFE Plus

FFEPlus adalah sebuah solver iterative yang menggunakan metode integrasi implisit. Iterasi terus dilanjutkan sampai kesalahan cukup kecil. Secara umum solver ini lebih akurat dan efisien untuk pemecahan persoalan dengan derajad kebebasan lebih dari 100.000.

b. Direct Sparse

Menghasilkan sebuah direct solution menggunakan tehnik numerik. Direct sparse merupakan sebuah solver yang cepat bila terdapat memori yang cukup. Pada umunya solver ini digunakan pada permasalahan yang kecil atau medium.

c. Large Problem Direct Sparse (LPDPS Solver)

LPDS solver adalah solver Direct Sparce yang bisa menghitung menggunakan multiple core, digunakan jika dibutuhkan dan terjadi lack pada RAM akibat ruang yang tidak cukup.

d. Auto

Pada pilihan Auto, pemecahan masalah akan menggunakan solver FFEPlus secara otomatis, sampai terdapat batasan tertentu selama proses menjalankan solvers.

Dalam kasus analisa sambungan las ini, akan digunakan solver tipe Auto, sehingga solidworks memiliki kebebasan untuk menentukan sendiri solver yang sesuai.

\subsubsection{Interpretasi Dan Analisa Hasil Simulasi Solidworks.}

Interpretasi hasil simulasi dengan menggunakan solidworks dilakukan dengan beberapa langkah sebagai berikut :

\section{a. Tegangan Von Mises}

Stres Von Mises digunakan untuk menentukan apakah material akan mengalami tegangan bila dikenai pemuatan tertentu. Stres von Mises dihitung dan kemudian dibandingkan dengan tegangan hasil material. Ini disebut Von Mises Yield Criterion [13]. Von Mises adalah proses empiris yang harus diverifikasi melalui pengamatan dan pengalaman yang berbeda, bukan teori atau penalaran yang dipaksakan [14]. Pada kasus analisa ini dimana elemen shell yang dipakai untuk meshing, maka tegangan resultan maksimum yang terjadi adalah tegangan kombinasi antara axial dan bending, proses pemilihan output tegangan ditunjukan pada Gambar 11.

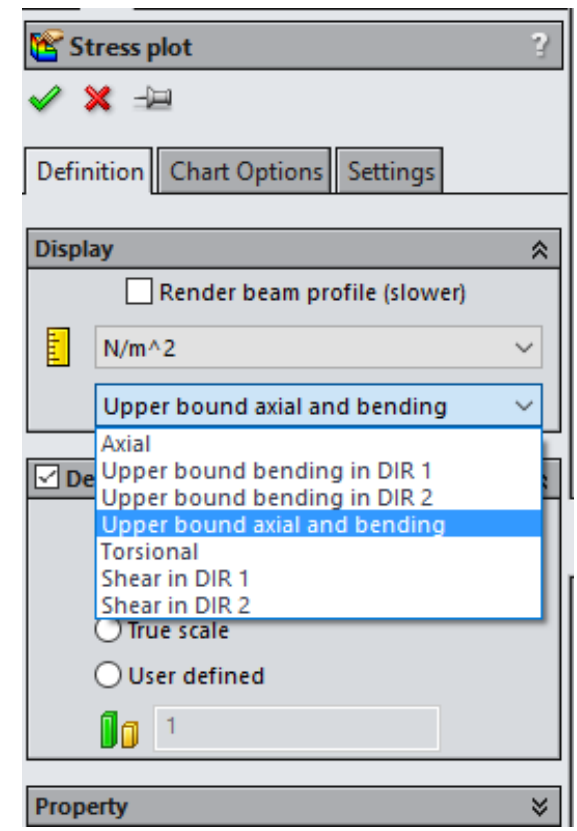

\section{Gambar 11. Pembuatan Plot Tegangan Pada Solidworks}

Besarnya tegangan maksimum yang terjadi pada sambungan las ditunjukan pada Gambar 12 . 


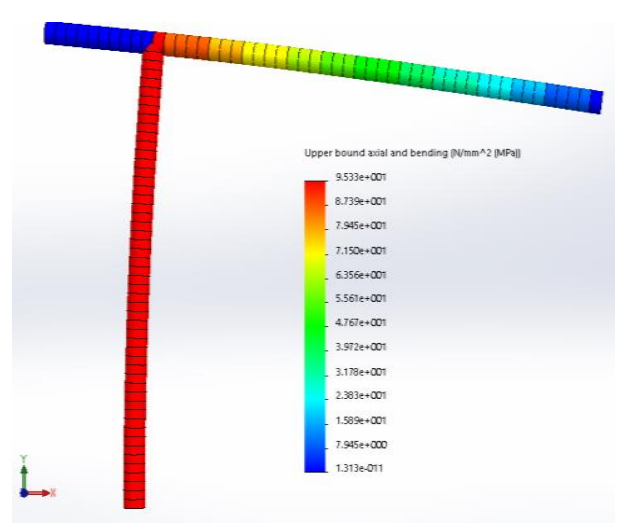

\section{Gambar 12. Tegangan Maksimum Pada Model Sambungan}

Simulasi pada model solidworks memberikan hasil berupa tegangan yang terjadi pada sambungan, mode getaran frekuensi pribadi, dan defleksi yang terjadi. Dari hasil plotting, pada beban $1000 \mathrm{~N}$ didapat nilai tegangan maksimum 95,33 Mpa. Nilai yield strength yang dimiliki material yaitu sebesar $245 \mathrm{MPa}$. Bila dibandingkan nilai tegangan hasil simulasi dan tegangan ijin material, maka berdasarkan resultan, atau biasa disebut energi distorsi hasil tegangan simulasi dapat diterima [15].

b. Plotting Hasil

Tegangan resultan tidak akan memberikan interpretasi yang akurat, perlu juga untuk mencari tegangan $1^{\text {st }}$ dan $2^{\text {nd }}$ tegangan principal pada model [15]. Bentuk tegangan akibat beban lain pada model ditunjukan pada Gambar 11.

(a)

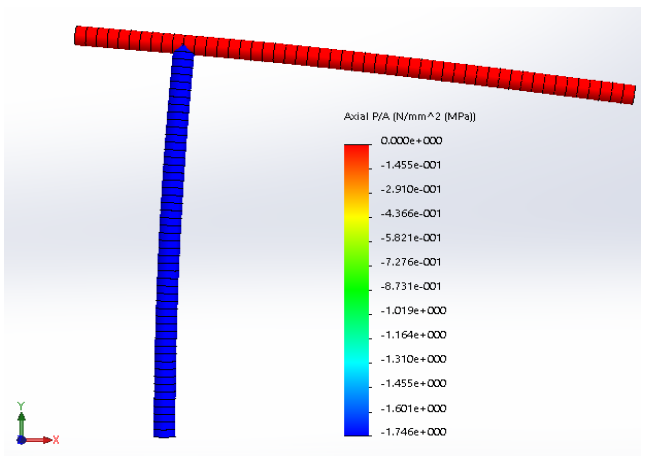

(b)

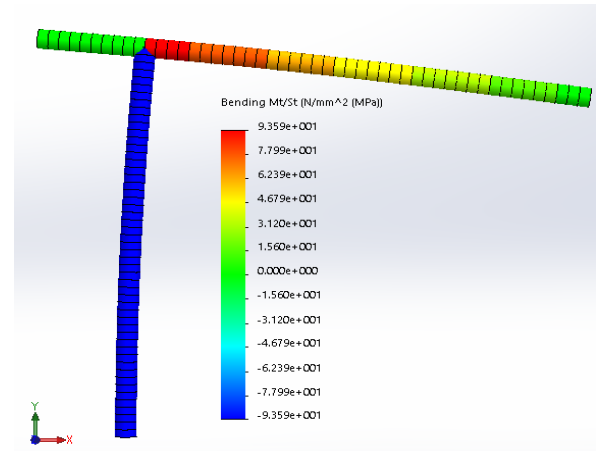

(c)

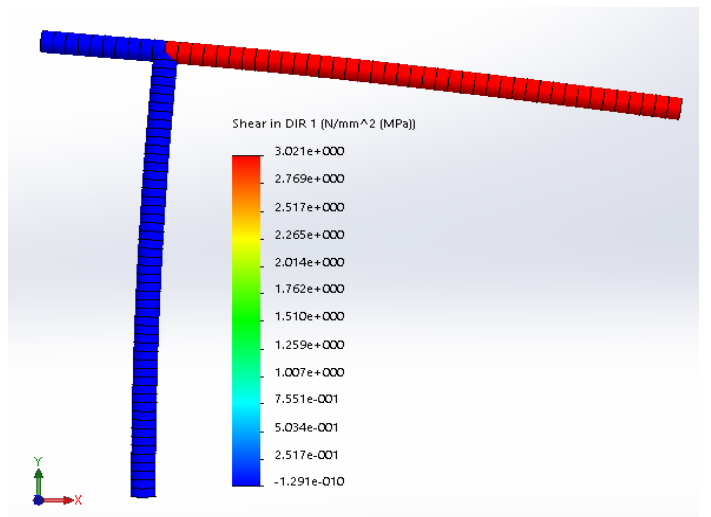

Gambar 13. Beberapa Jenis Tegangan Pada Model Sambungan: (a) Tegangan Axial, (b) Tegangan Bending Arah $2^{\text {nd }}$, Dan (c) Tegangan Geser Arah $1^{\text {st }}$

Dari hasil simulasi diketahui nilai tegangan axial sebesar 0,1455 MPa, tegangan geser $1^{\text {st }}$ sebesar 3,021 MPa dan tegangan bending $2^{\text {nd }}$ yang terjadi sebesar 93,59 MPa. Bila dibandingkan antara tegangan von mises dengan tegangan lainya yang terjadi, maka besar tegangan resultan $(95,33$ 
$\mathrm{MPa}$ ) masih lebih besar dari tegangan lainya, sehingga tegangan resultan tetap dijadikan sebagai acuan untuk melakukan analisa keamanan struktur sambungan las.

c. Defleksi

Besarnya defleksi untuk simulasi ini dalam satuan URES (mm), URES berarti besaran dari vektor defleksi yang dihitung secara resultan [16]. Bila dituliskan dalam persamaan, nilai URES dapat dijabarkan seperti pada Persamaan 1 berikut :

$U R E S=\sqrt[2]{U x^{2}+U y^{2}+U z^{2}}$

(1)

Dimana :

URES :besaran defleksi resultan (mm)

Ux $\quad$ :besaran defleksi arah sumbu $\mathrm{x}(\mathrm{mm})$

Uy :besaran defleksi arah sumbu y $(\mathrm{mm})$

$U z \quad$ :besaran defleksi arah sumbu z $(\mathrm{mm})$

Pada simulasi model sambungan dimana model diberi beban, maka sambungan akan mengalami defleksi dengan nilai defleksi dapat dilihat pada Gambar 14.

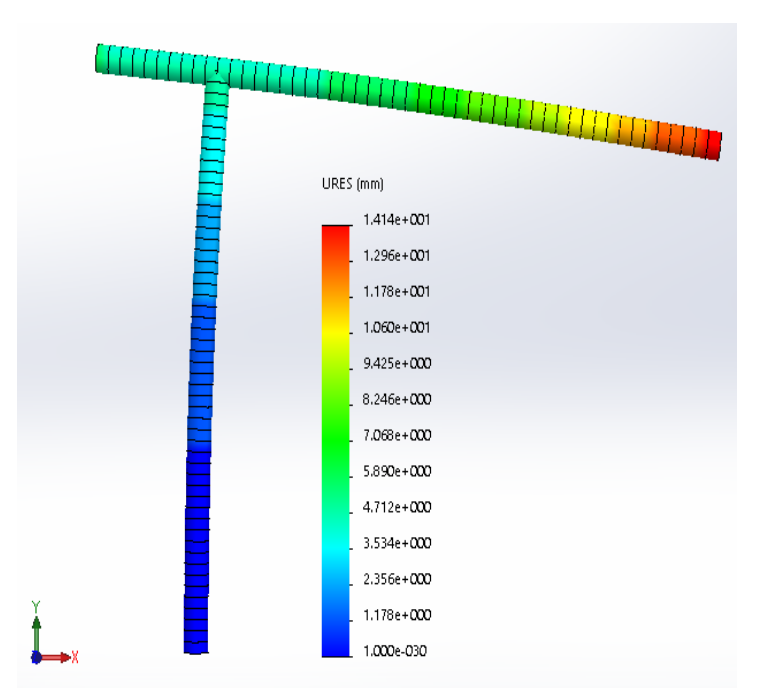

Gambar 14. Defleksi Yang Terjadi Pada Sambungan

Besar defleksi resultan yang terjadi adalah 14,14 mm. Arah defleksi dominan pada sumbu y.

\subsection{Percobaan Lab}

Untuk membuktikan kebenaran simulasi FEM yang telah dilakukan, maka selanjutnya dilakukan validasi dengan pengujian pada spesimen sambungan las skala penuh.

\subsubsection{Spesimen Sambungan Las}

Bentuk spesimen sambungan dapat dilihat pada Gambar 3 dan Gambar 4. Sambungan tersebut berupa hasil pengelasan dari 2 struktur rangka dengan fungsi berbeda.

\subsubsection{Alat Pengujian}

Daftar alat yang digunakan untuk melakukan uji kesesuaian sambungan mengacu pada standard ADR ditunjukan pada Tabel 2. 
Tabel 2. Daftar peralatan uji sambungan las

\begin{tabular}{lll}
\hline No & Nama & Fungsi \\
\hline 1 & Aktuator 20 kN & Sumber beban \\
2 & Kelsey Controler & Alat Kontrol beban \\
3 & XY Recorder & Pencatat gerakan aktuator dan besar beban \\
4 & Jig-Rig & Alat bantu untuk tumpuan dan pencekam specimen \\
5 & Calliper & Pengukur dimensi tebal \\
6 & Penggaris & Pengukur dimensi panjang \\
\hline
\end{tabular}

Alat uji aktuator, jig-rig, kontroler dan x-y Recorder yang digunakan dalam uji ini dapat dilihat pada

\section{Gambar 15.}

(a)

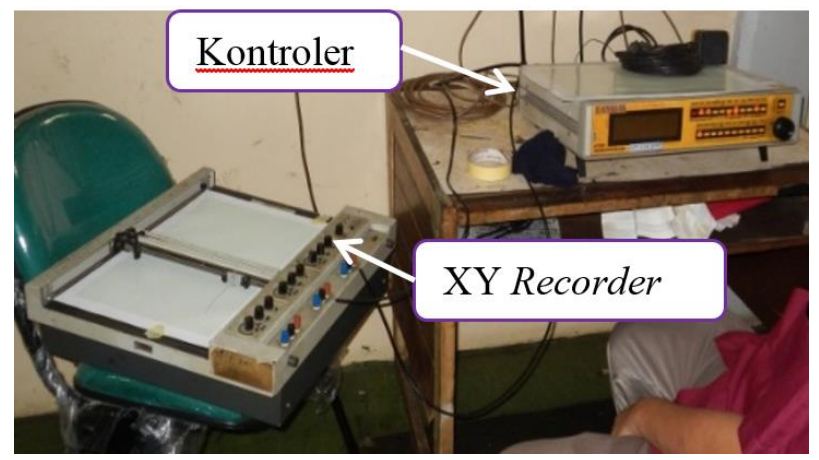

(b)

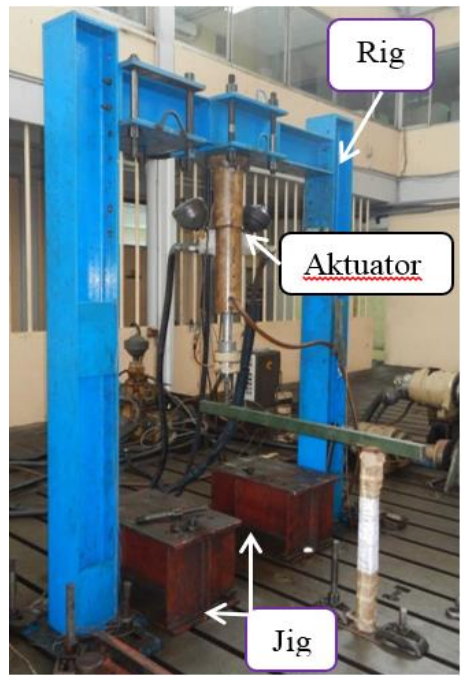

Gambar 15. Alat Uji Yang Digunakan: (a) Alat Kontrol Dan XY Recorder, Dan (b) Aktuator

\subsubsection{Set Up Spesimen}

Pada proses pengujian, spesimen sambungan las diletakkan diatas jig, supaya spesimen tidak jatuh, maka bagian floor bearer spesimen di pegang dengan baut pemegang pada jig. Beban dibangkitkan oleh aktuator, selanjutnya diteruskan ke spesimen dengan menggunakan 2 tumpuan beban di kedua ujung hoop pillar. Set up spesimen uji pada rangka atau jig dan mesin uji supaya sesuai dengan kebutuhan disain dapat dilihat pada

Gambar 16. 


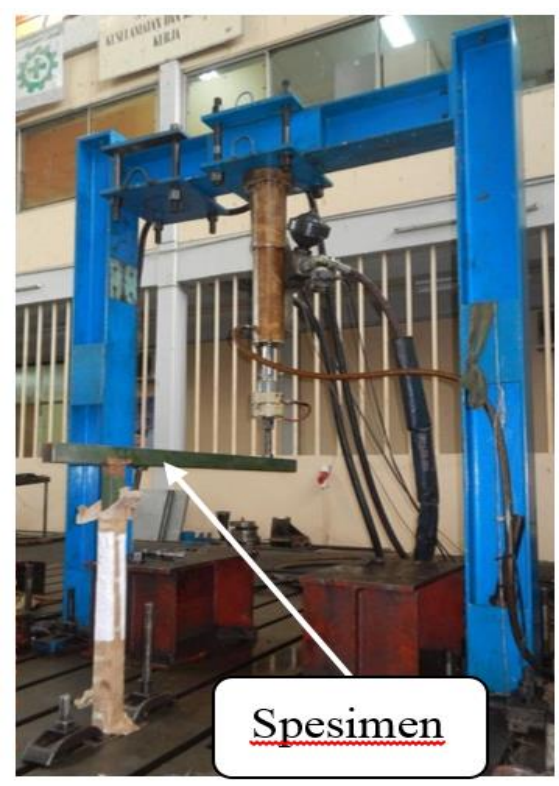

\section{Gambar 16. Set Up Spesimen Sambungan Las Pada Jig}

\subsubsection{Proses Pengujian}

Pengujian dilakukan dengan membangkitkan beban melalui aktuator secara bertahap dari beban $0 \mathrm{~N}$ sampai beban tertentu (1000 N), dimana defleksi yang terjadi akan mengikuti besarnya beban. Proses pengujian sambungan las ditunjukan pada

Gambar 17.

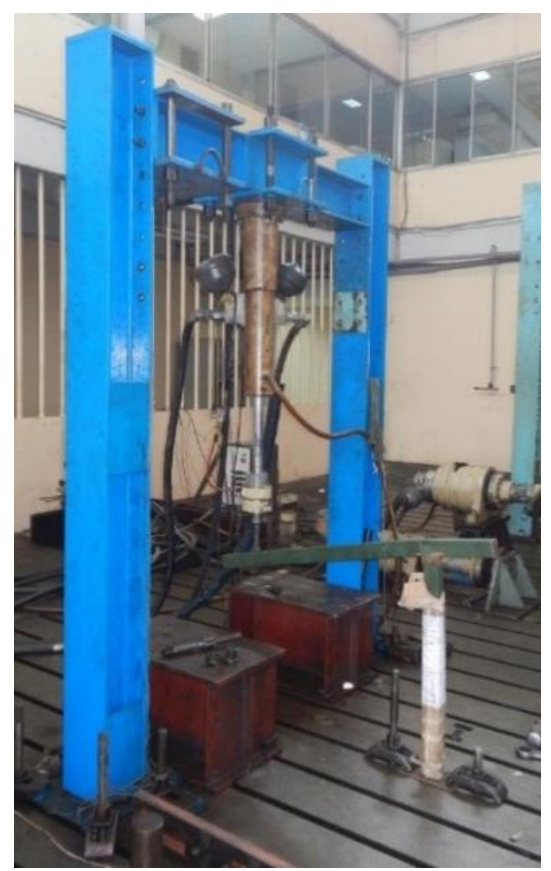

Gambar 17. Proses Pemberian Beban Pada Spesimen Sambungan Las

Selama proses pengujian berlangsung nilai beban dan defleksi yang terjadi pada spesimen di rekam pada kertas milimeter menggunakan alat XY Recorder.

\subsubsection{Hasil Uji}

Hasil pengujian berupa grafik beban vs defleksi, grafik ini menggambarkan besarnya defleksi yang terjadi diakibatkan oleh pemberian beban pada spesimen. Grafik defleksi vs beban ditunjukan pada Gambar 18. 


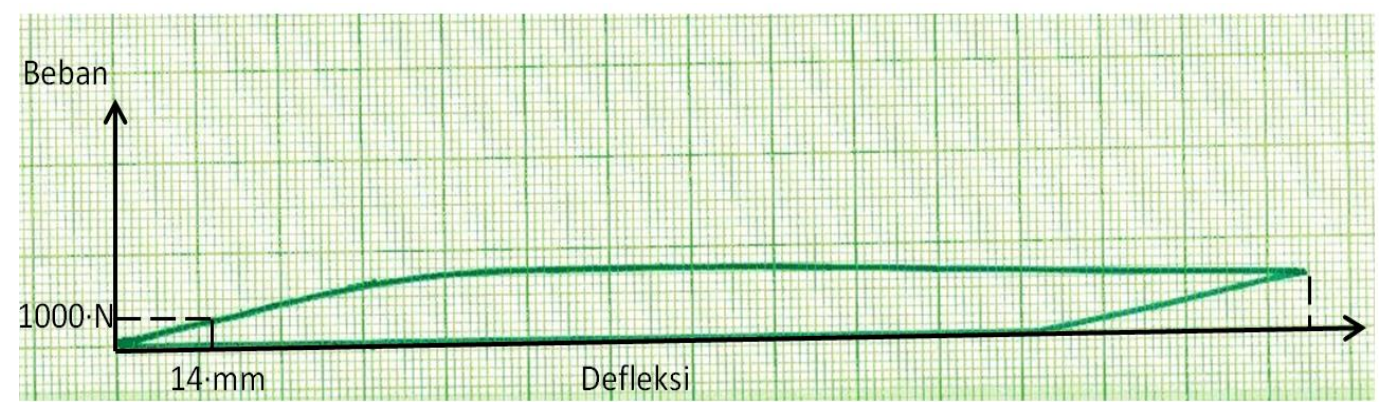

Gambar 18. Grafik Beban VS Defleksi Pada Sambungan Las

Berdasarkan diagram diatas diketahui, pada beban $1000 \mathrm{~N}$ maka besarnya defleksi yang terjadi adalah $14 \mathrm{~mm}$. Spesimen sambungan las setelah dilakukan uji mengalami deformasi permanen seperti ditunjukan pada

Gambar 19. Walaupun rangka sambungan mengalamai deformasi, namun sambungan las tidak mengalami kerusakan.

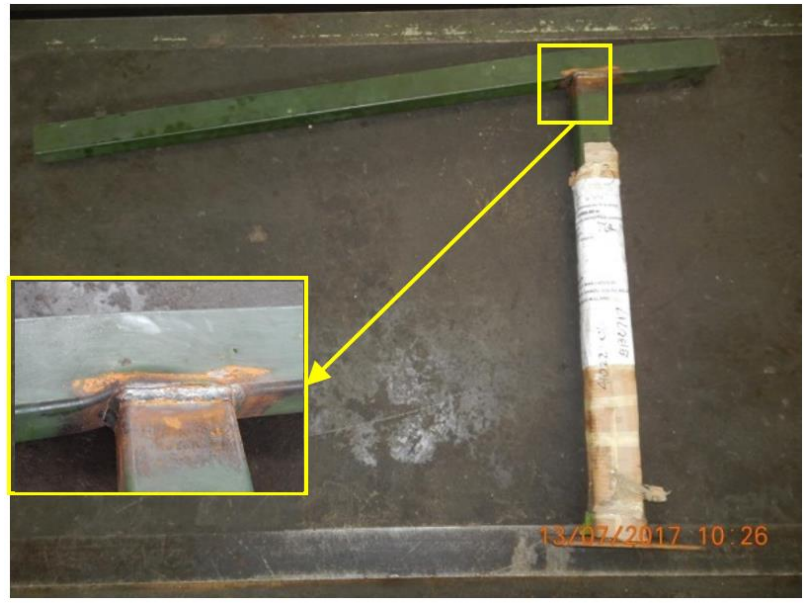

Gambar 19. Spesimen Sambungan Las Setelah Dilakukan Pengujian

\section{KESIMPULAN}

Berdasarkan hasil simulasi FEM menggunakan software solidworks, pada beban $1000 \mathrm{~N}$ diperoleh nilai defleksi yang terjadi adalah $14,14 \mathrm{~mm}$, sedangkan berdasarkan hasil uji pada spesimen sambungan las diperoleh defleksi yang terjadi sebesar $14 \mathrm{~mm}$, nilai hasil simulasi terpaut tidak jauh dengan hasil uji, sehingga hasil simulasi bisa diterima. Berdasarkan hasil ini maka dapat diketahui bahwa proses simulasi sambungan las menggunkan solidworks sudah benar. Proses simulasi sambungan las ini dapat digunakan menggunakan Meshing tipe elemen Shell dan keluaran defleksi URES.

\section{DAFTAR PUSTAKA}

[1] SAFE JOINT. 2017. "Enhancing structural efficiency through novel dissimilar material joining techniques". European Project FP7-NMP-2012-SMALL-6.

[2] Pedro Galvez . 2017. "Study of the behaviour of adhesive joints of steel with CFRP for its application in bus structures".

[3] A. Subic, J. He and S. Preston. 2010. "Modal analysis of Bus Roll cage structure for optimum rollover design". The International Society for Optical Engineering.

[4] Australian Design Rule (ADR) 59/00 Part A Tahun 1992. “Omnibus Rollover Strength". Australian Government, Department of Infrastructure, Regional Development and Cities.

[5] Parisi, F, 2017. "Structural failure investigations through probabilistic nonlinear finite element analysis: Methodology and application". Engineering Failure Analysis 80, 386-402

[6] Caglayan, O. 2007. "Experimental and finite element investigations on the collapse of a Mero space truss roof structure - A case study". Engineering Failure Analysis 15, 458-470

[7] Delatte, N. 2010. "Failure literacy instructural engineering”. Engineering Structures 32, 1952-1954 
[8] SIMULIA Community News. (2017). The Future Of Manufacturing Better Materials- Innovative Solutions. Dassault Systemes.

[9] Paul M.Kurowski. (2012). Engineering Analysis with SolidWorks Simulation 2012. Schroff Development Corporation.

[10] DRISS, Z. 2015. "Study of the meshing effect on the numerical results of a NACA2415 airfoil wind turbine ". Congrès Français de Mécanique 22ème.

[11] Dhaimi, Imane. 2016. "Load Stress Distribution In a Typical Small Wind Turbine Structure In Static Conditions". Capstone Final Report.

[12] Joe. (2011). Choosing a Solver in SolidWorks Simulation. GoEngineer.

[13] Malvern, L.E. (1969). Introduction to the Mechanics of a Continuous Medium. Prentice Hall.

[14] Dassault Systemes SolidWorks Corporation. (2017). WHAT'S NEWSOLIDWORKS 2017. Dassault Systèmes SE company.

[15] Richard G. Budynas and J. Keith Nisbett. (2016). Shigley's Mechanical Engineering Design. $9^{\text {th }}$ Ed. McGraw-Hill.

[16] J. E. Akin. (2010). Finite Element Analysis Concepts via SolidWorks. Word Scientific 